\title{
Welfare costs of inflation in a dynamic economy with search unemployment
}

\section{Burkhard Heer}

University of Bamberg and CESifo*

JEL classification: E31; E41; E52; J64

Key words: Welfare costs of inflation; Money demand; Search unemployment; Transition dynamics

\begin{abstract}
We present a monetary general equilibrium model with labor market frictions in the form of search unemployment which is calibrated for the US economy. Interestingly, both employment and output may even increase with the rate of inflation depending on the elasticity of labor supply. Considering the transition dynamics following a change in the monetary policy, the optimal quarterly inflation rate is found to amount to approximately $-0.6 \%$ in the benchmark case. A reduction of the inflation rate from its current level to its optimal value only results in small welfare gains equal to $0.08 \%$ of total consumption.
\end{abstract}

${ }^{*}$ Burkhard Heer, University of Bamberg, Department of Economics, Feldkirchenstrasse 21, 90651 Bamberg, Germany. Tel.: +49-(0)951-863-2634, fax: +49-(0)951-863-2635.

E-mail address: Burkhard.Heer@sowi.uni-bamberg.de.

Acknowledgements: Preliminary versions of this paper have been presented at the World Congress of the Econometric Society in Seattle, the CESifo Area Conference on Macro, Money \& International Finance in Munich, and at research seminars at the Bank of England, the European Central Bank, and Konstanz. I would like to thank C. Evans, A. Razin, H.-W. Sinn, and an anonymous referee for helpful comments. All remaining errors are mine. 


\section{Introduction}

Lucas (2000) argues that the money holding behavior at very low interest rate is central for estimating welfare costs of inflation. Furthermore, he provides estimates of the welfare costs of inflation. A reduction in the inflation rate from 10 percent to zero implies steady-state welfare gains of approximately one percent of real income. In order to derive his results, he calibrates both the Sidrauski model and the McCallum-Goodfriend model with the help of observations from the US economy. He concludes that the optimal monetary policy in these two models consists of a deflation consistent with a zero or near-zero nominal interest rate as advocated by Friedman (1969).

In a variety of recent studies on the optimal quantity of money and the optimality of the Friedman rule, the use of cash has been motivated with a cash-in-advance constraint provided in Lucas and Stokey $(1983,1987) .{ }^{1}$ In the presence of a cash-in-advance constraint, higher inflation reduces the return from working as income earned in the previous period cannot be spent on the cash good until the next period. As a consequence, households substitute leisure for labor and employment and output decline. In the cash-in-advance economy of Cooley and Hansen (1989), the optimal growth rate of money entails a zero nominal interest rate so that the cash-in-advance constraint does not bind. They estimate the welfare costs of a reduction from an annual inflation rate of $10 \%$ to the optimal rate to amount to approximately $0.1-0.4 \%$ of GNP, depending on the measurement of money by either the monetary base or M1.

Over the last decade, two different questions with regard to the welfare costs of inflation have been extensively analyzed in the general equilibrium model

\footnotetext{
${ }^{1}$ Two other popular frameworks for the analysis of the optimality of the Friedman rule are the shopping time model and the money-in-the-utility model. See e.g. Woodford (1990), Guidotti/Végh (1993), Correia/Teles (1996, 1997), or Chari et al. (1996).
} 
with a cash-in-advance constraint based on Lucas/Stokey $(1983,1987)$ : i) is the Friedman rule of a zero nominal interest rate still optimal in economies with distorting taxes, and ii) what is the (quantitative) effect of inflation on welfare if monetary policy affects the growth rate of the economy. The first question is answered using standard results from public finance (as in Diamond/Mireless, 1971a, 1971b), e.g. in the studies of Cooley/Hansen (1991), Gillman (1993), or Chari et al. (1996). The second question is examined in models of endogenous growth where inflation reduces the growth rate. In Gomme (1993), endogenous growth arises through human capital accumulation as in Lucas $(1988,1990)$. A $10 \%$ money growth rate (8.5\% inflation rate) results in welfare costs of no more than $0.03 \%$ of income. Wu and Zhang (1998) analyze a monetary endogenous growth model based on Romer (1986). They find significant welfare costs of inflation in the range from half to $5 \%$ points for an annual monetary growth of 10\%. Different from Gomme (1993), the growth rate effect is important in their model.

In the present paper, we also analyze the welfare costs of inflation in a monetary general equilibrium model with a cash-in-advance constraint. However, our direction of research is different from the above studies which all assume Walrasian labor markets. Our model is based on Pissarides (1990). Unemployment results from time-consuming and costly matching of vacancies with searching agents. The presence of search unemployment and wage bargaining is shown to have an impact on optimal monetary policy. We find that inflation may help to increase employment. Furthermore, even though the Friedman rule may not be optimal, the resulting welfare losses from such a deflationary monetary policy are of small magnitude.

At first glance, this result is surprising. Following a rise in the inflation rate, agents substitute search for leisure, similar to the leisure-labor substitution effect in Cooley/Hansen (1989) or in the endogenous growth models 
of Gomme (1993) and Wu/Zhang (1998). The reduction in search effort reduces the probability of firms to fill a job and tends to decrease employment. However, in our model, there is also an opposing employment-enhancing effect from a rise in the rate of inflation. High inflation also reduces the level of consumption (relative to the one of capital) as agents substitute real money balances and capital as in Tobin (1965). In our economy, wages result from decentralized Nash bargaining. Following a decline in consumption, the reservation wage of the households and, hence, the bargained wage decrease. Consequently, firms increase their vacancies, which boosts employment. ${ }^{2}$ The net effect of a rise of inflation on employment is positive for our benchmark calibration of the model for the US economy, but is shown to crucially depend on the labor supply elasticity.

In addition to other studies on the welfare effects of inflation such as Cooley/Hansen (1989) or Lucas (2000), we will also account for the transition dynamics following a change in the money growth rate. Recent quantitative evaluations of policy measures find a significant effect of transition dynamics on welfare. For example, Lucas (1990) analyzes the abolition of capital income taxes in an endogenous growth model with human capital accumulation. In steady state, the change in welfare amounts to a $3 \%$ consumption equivalent increase. As demonstrated by Grüner/Heer (2000), also considering the transition from the old to the new steady state reduces the welfare gain of such a policy to $1 \%$ of total consumption. Furthermore, in our model of search unemployment, the transition dynamics and hence welfare results may be different from the one in standard models with Walrasian labor markets. Typically, welfare is measured by life-time utility of the households which is a function of leisure and consumption. Following a policy change,

\footnotetext{
${ }^{2}$ This effect is not confined to cash-in-advance models, but would also be present in other monetary general equilibrium, e.g. a shopping time model, as soon as we introduce search unemployment and wage bargaining.
} 
consumption and leisure immediately adjust in standard monetary general equilibrium models, ie they are jump variables. However, in the presence of labor market frictions, employment behaves fundamentally different and only adjusts gradually to the new steady state, ie employment is a sluggish variable.

Consequently, the magnitude of instantaneous utility during transition differs significantly from the one in the new steady state and the analysis of the balanced-growth path without any further consideration of the transition might even lead to the wrong policy conclusion.

Our model extends the search unemployment model of Shi/Wen (1999) by introducing a role for money with the help of a cash-in-advance constraint. The monetary general equilibrium model is presented in section 2 . In section 3 , the model is calibrated for the US economy using standard parameters from applied general equilibrium studies. We also briefly describe our computational methods. Section 4 presents a balanced-growth analysis. As one major result, inflation is shown to possibly increase employment, production, and steady-state utility in the presence of search unemployment and wage bargaining. In section 5, the welfare costs of inflation are analyzed explicitly accounting for the transition dynamics. As our second major result, the optimal nominal interst rate is shown to be close but not equal to zero for realistic values of labor market parameters. Section 6 concludes.

\section{The model}

The model introduces money demand in the search model of Shi/Wen (1999). Four sectors can be distinguished: households, firms, the government, and the monetary authority. The representative household maximizes his expected intertemporal utility subject to his budget constraint. Firms produce 
a consumption-investment good using capital and labor. Labor markets are subject to frictions as matching vacancies with searching workers is a timeconsuming transaction. Wages are bargained and deviate from the marginal product of labor. Money is incorporated into the model using a cash-inadvance constraint.

\section{$2.1 \quad$ Households}

Households are of measure one. The representative household consists of different members who pool their receipts. Agents either work, search for a job, or enjoy leisure. Let $n$ denote the share of agents working, $s$ the share of agents searching, and $1-n-s$ denote the unemployed agents not actively searching for a job. $n, s$, and $1-n-s$ can also be interpreted as the number of employed agents, the number of unemployed agents, and the number of agents who are out of the labor force. All variables are indexed by time, which is continuous. For convenience, we omit the time index. Furthermore, working $n$ and searching $s$ is assumed to cause disutility to the agents.

Households maximize their intertemporal utility

$$
\int_{0}^{\infty} U(c, s, n) e^{-\rho t} d t=\int_{0}^{\infty}\left[\frac{c^{1-\sigma}}{1-\sigma}-\beta \frac{(n+s)^{\eta}}{\eta}\right] e^{-\rho t} d t
$$

where $c, \rho$, and $1 / \sigma$ denote consumption, the discount rate of the household, and the intertemporal elasticity of substitution, respectively.

As a distinguishing feature of this economy, employment $n$ changes only gradually:

$$
\dot{n}=q s-\theta n,
$$

where $q$ denotes the probability of the searching agents to find a job. The individual agents take $q$ as given, while it is determined endogenously in the 
labor market. Finding a job takes time. As a possible explanation, workers and firms are placed in different locations or the screening and dissemination of information is a time-consuming activity. Furthermore, workers are separated from their job at the rate $\theta$, which is given exogenously.

Households face two constraints, a budget constraint and a cash-in-advance (CIA) constraint. They receive income from capital $k$, labor $n$, profits $\Omega$, and real lump-sum transfers $t r$ from the monetary authority. Real assets $a$ consist of capital $k$ and real money balances $m$ and accumulate according to:

$$
\dot{a}=\dot{k}+\dot{m}=\left(1-\tau_{w}\right) w n+r k+\Omega+t r-c-\pi m,
$$

where $w, r$, and $\pi$ denote the wage rate, the interest rate, and the inflation rate, respectively. The government taxes wage income at rate $\tau_{w}$. Furthermore, the initial endowments at time zero $k_{0}$ and $n_{0}$ are given.

The consumption good $c$ consists of $\psi c$ cash goods and $(1-\psi) c$ credit goods. Purchases of the cash good are subject to the CIA constraint: ${ }^{3}$

$$
\psi P c \leq P m
$$

where $P$ denotes the price level with $\pi \equiv \frac{\dot{P}}{P}$. Since the analysis only considers the situation $\pi \geq-r$, equation (4) will always hold as an equality at an optimum. $^{4}$

In the case of an interior solution, $s, n, 1-n-s>0$, the first-order conditions of the household are given by:

$$
\frac{\dot{c}}{c}=\frac{1}{\sigma}\left[r-\rho-\frac{\psi \dot{\pi}}{1+\psi(r+\pi)}-\frac{\psi \dot{r}}{1+\psi(r+\pi)}\right],
$$

\footnotetext{
${ }^{3}$ The CIA-constraint is equivalent to the deposit-in-advance constraint used by Edwards/Végh (1997) in a small open-economy model with pre-determined exchange rates.

${ }^{4}$ If capital $k$ earns a gross nominal return $1+r+\pi$ less than one, then the consumer can make profits by buying money and selling capital. Thus, in an equilibrium with strictly positive capital stock and production, $\pi \geq-r$.
} 


$$
\begin{aligned}
q \phi & =\beta(s+n)^{\eta-1}, \\
\dot{\phi} & =(\theta+\rho) \phi+\beta(s+n)^{\eta-1}-\frac{w}{c^{\sigma}} \frac{1-\tau_{w}}{1+\psi(r+\pi)},
\end{aligned}
$$

where $\phi$ denotes the current value shadow price of employment to the household. Equations (5) and (7) describe the dynamics of consumption $c$ and the current value shadow price of employment, $\phi$. According to equation (6), the marginal benefit of search, $q \phi$, is equal to the marginal cost of search, $\beta(s+n)^{\eta-1}$.

\subsection{The monetary authority}

The economy-wide nominal money supply $M=P m$ grows at the rate $\mu$ :

$$
\frac{\dot{M}}{M}=\mu \text {. }
$$

The seignorage obtained from money creation is paid to the households as a lump-sum transfer implying:

$$
\operatorname{tr}=\mu m
$$

\section{$2.3 \quad$ Firms}

Firms are identical and of measure one. They use labor $n$ and capital $k$ in order to produce the consumption-investment good $y$ with the technology $f(k, n)$. Production is characterized by constant-returns to scale and assumed to be Cobb-Douglas:

$$
y=f(k, n)=A k^{\alpha} n^{1-\alpha}
$$

Output $y$ can either be consumed by the households or accumulated.

Firms maximize discounted profits:

$$
\int_{0}^{\infty} \Omega e^{-\int_{0}^{t} r(h) d h} d t
$$


where profits are given by:

$$
\Omega=f(k, n)-(r+\delta) k-w n-\kappa v+\tau_{i}(\dot{k}+\delta k) .
$$

Firms take the interest rate $r$ and the wage rate $w$ as given. Capital depreciates at the rate $\delta$. The cost of maintaining a number of job vacancies $v$ is equal to $\kappa v$. The vacancy costs $\kappa v$ represent real costs of production for hiring, screening, or training of workers. $\tau_{i}$ denotes the investment tax credit.

Workers separate from a job at rate $\theta$. The individual firm takes the rate $\vartheta$ at which a vacancy is filled as given. The firm's employment evolves according to:

$$
\dot{n}=\vartheta v-\theta n \text {. }
$$

The maximization conditions of the firm are as follows:

$$
\begin{aligned}
f_{k}(k, n) & =\left(1-\tau_{i}\right)(r+\delta), \\
\kappa & =\nu \vartheta, \\
\dot{\nu} & =(\theta+r) \nu-\left(f_{n}(k, n)-w\right),
\end{aligned}
$$

where $\nu$ and $f_{i}(k, n)$ denote the current value shadow price of employment to the firm and the marginal product of $i, i=k, n$, respectively. According to the optimal decision on the capital stock $k$, equation (14), the marginal product of capital equals the interest rate $r$ plus depreciation $\delta$ net of the investment tax. In equation (15), the marginal cost of a vacancy $v$ is equated to its marginal benefit. The dynamics of the current value shadow price of employment $\nu$ are described by equation (16).

\subsection{The government}

The government receives revenues from taxing labor income. The government budget is balanced at any time so that government expenditures consisting 
of investment tax credits, $\tau_{i}(\dot{k}+\delta k)$, equal labor income taxes $\tau_{w} w n$ :

$$
\tau_{i}(\dot{k}+\delta k)=\tau_{w} w n
$$

\subsection{Matching and wage determination}

Labor markets are subject to frictions and are characterized by two-sided search. Time is needed in order to match vacancies with searching workers. Furthermore, there is an externality from searching and posting a vacancy. An increase in the number of searchers reduces the probability of other searching agents to find a job, while it increases the probability of firms to fill their vacancies. Vice versa, an additional vacancy increases the probability of a searching agent to get a job, while it reduces the probability of the other firms to fill a vacancy. Thus, a negative externality arises whenever the number of active agents increases on the same side of the market and a positive externality arises if the number of agents increases on the other side of the market.

In order to simplify notation, let $v$ and $s$ also denote the aggregate numbers of vacancies and searching agents, respectively. The number of aggregate matches $L$ is an increasing function of both aggregate vacancies $v$ and aggregate searching agents $s$. If no vacancy is posted $(v=0)$, no jobs can be matched, $L=0$. Similarly, if agents are not searching for a job $(s=0)$, $L=0$. In particular, the flow of job matches $L$ is described by the following constant returns to scale technology:

$$
L=L_{0} v^{\gamma} s^{1-\gamma}, \quad L_{0}>0,0<\gamma<1 .
$$

The job finding rate of the searching agents is given by $q=\frac{L}{s}$, while the firms fill a vacancy at rate $\vartheta=\frac{L}{v}$. In equilibrium, the number of agents finding a job is equal to the number of filled vacancies, $\vartheta v=q s$. 
Wages result from decentralized bargaining between the firm and the marginal worker. Both the firm and the worker receive a rent from a successful match. More specifically, the wage is determined by Nash bargaining which maximizes a product of weighted surpluses of the household and the firm:

$$
\max _{w}\left[f_{n}(k, n)-w\right]^{1-\lambda}\left[w-\beta(s+n)^{\eta-1} \frac{c^{\sigma}}{1-\tau_{w}}\right]^{\lambda}
$$

where $\lambda$ measures the bargaining power of the workers. The term $\beta(s+$ $n)^{\eta-1} c^{\sigma} /\left(1-\tau_{w}\right)$ can be interpreted as the agent's reservation wage. ${ }^{5}$

The wage as resulting from the Nash bargaining problem is given by:

$$
w=\lambda f_{n}(k, n)+(1-\lambda) \beta(s+n)^{\eta-1} \frac{c^{\sigma}}{1-\tau_{w}} .
$$

The wage is lower than the marginal product of labor and exceeds the reservation wage of the household. Accordingly, both agents share a rent, the shares depending on the bargaining power $\lambda$.

\subsection{Competitive search equilibrium}

Definition. The competitive search equilibrium is a collection of decision rules $\{c, s, v, k\}$ and prices $\{w, r, \pi\}$ such that

1. Individual variables equal aggregrate variables.

2. Households maximize their utility (1) subject to (2), (3), and (4).

3. Firms maximize profits (11) subject to (12) and (13).

4. Wages and interest rates are given by (20) and (14), respectively.

5. Assets accumulate according to (3).

\footnotetext{
${ }^{5}$ For a discussion of the wage determination see Shi/Wen (1999).
} 
6. Agents do not take into account the effect of their decisions on the matching rates $q$ and $\vartheta: \vartheta v=q s$.

7. Employment evolves according to (2).

8. Nominal money grows at the exogenous rate $\mu$.

9. The goods market clears:

$$
\dot{k}=f(k, n)-\delta k-c-\kappa v .
$$

10. The government budget (17) balances.

In equilibrium, our economy can be described with the help of the initial endowment of labor $n_{0}$ and capital $k_{0}$ and the following dynamic equations in the variables $c, \phi, \nu, n, r, \pi$, and $k$ :

$$
\begin{aligned}
\frac{\dot{\pi}}{\pi} & =(\sigma(\pi-\mu)+r-\rho) \frac{1+\psi(r+\pi)}{\psi \pi}-\frac{\dot{r}}{\pi}, \\
\left(1-\tau_{i}\right) \dot{r} & =\alpha(1-\alpha) A\left(\frac{n}{k}\right)^{1-\alpha}\left(\frac{\dot{n}}{n}-\frac{\dot{k}}{k}\right) .
\end{aligned}
$$

together with equations (2), (5), (7), (16), and (21). The variables $w, q, s$, $v$, and $\tau_{w}$ are given by the non-linear equations (6), (16), (17), (20), and

$$
q=L_{0}\left(\frac{v}{s}\right)^{\gamma}
$$

The local behavior of the model's dynamics is studied by Shi/Wen (1997) for the case of constant search intensity $s$. Given $s=s_{0}$, the steady state is proven to be locally stable if the intertemporal elasticity of substitution, $1 / \sigma$, is sufficiently large. In the present model with endogenous search intensity $s$, the stability of the steady state can only be shown numerically for the specific calibration used. 


\section{Calibration and computation}

\subsection{Calibration}

The effects of a change in the inflation rate (as resulting from a change in the growth rate of money supply) cannot be studied analytically but only numerically. For this reason, the model is calibrated in order to match characteristics of the US economy. If not mentioned otherwise, our parameters are taken from Shi/Wen (1999). The unit time length corresponds to one quarter.

The production elasticity of private capital is set equal to $\alpha=0.25$. Capital depreciate at a rate of $\delta=0.01$. The parameter $A$ is normalized to one. The monetary parameters of the model are taken from Cooley/Hansen (1995). The quarterly growth rate of money supply is set equal to $\mu=0.013$. The share of consumption which is subject to the cash-in-advance constraint is set equal to $\psi=0.84$.

$<$ - insert table 1 here $->$

Following Shi/Wen (1999), the labor market parameters $\lambda, \gamma, L_{0}$, and $\theta$ are chosen as presented in table 1 . The discount rate of the households is set equal to $\rho=0.01, \eta$ is calibrated in order to obtain a labor supply elasticity of $\epsilon=1 /(\eta-1)=0.4$. Furthermore, the value of $\beta=2.596$ and $\kappa=4.01$ imply a steady state labor force participation $\bar{s}+\bar{n}=0.68$ and an unemployment rate $\bar{s} /(\bar{s}+\bar{n})=0.06$. Empirical estimates of the intertemporal elasticity of substitution, $1 / \sigma$, vary considerable. Real business-cycle models, as in Kydland and Prescott (1982) or Hansen (1985), apply a value of $\sigma$ equal to 
1.5 and 1.0, respectively, while Jones, Manuelli, and Rossi (1997) use values in the range of 1.0 to 2.5 in their endogenous growth model. In accordance with Shi and Wen (1999), we set $\sigma$ equal to 2.0 in the benchmark case.

In our benchmark case, the focus is on the analysis of the distortion caused by inflation in the presence of labor market search. For this reason, we do not introduce any further distortions in the first step of our analysis and do not allow for an active role of the government. Accordingly, the labor income tax rate $\tau_{w}$ and the investment credit rate $\tau_{i}$ are set equal to zero.

Our calibration implies a steady state quarterly inflation rate $\pi=1.3 \%$ and a quarterly real interest rate $r=1 \%$. The rate at which searching agents find a job and firms fill a vacancy amount to $q=0.783$ and $\vartheta=1.177$, respectively. The endogenous values of the consumption-output and the consumptioncapital ratio are equal to $c / y=0.801$ and $c / k=0.064$, respectively.

\subsection{Computation}

In section 5 , the transition dynamics of employment $n$, consumption $c$, capital $k$, search intensity $s$, and vacancies $v$ following a change in the money growth rate $\mu$ are presented. In order to solve for the transition dynamics, we have to solve a two-point boundary value problem. For the two sluggish variables, $n$ and $k$, two inital conditions, denoted by $n_{0}$ and $k_{0}$, are given. In the long run, the endogenous variables approach their new steady state values. Accordingly, the endpoints of all variables are known. Further, the new steady state is found to be locally stable for all cases considered in this paper. The Jacobian matrix of the differential equation system (2), (5), (7), (16), (21), (22), and (23) has two negative and five positive eigenvalues.

The numerical two-point boundary value problem is solved with the method 
of reverse shooting. ${ }^{6}$ For this reason, we perturbated the new steady state $\left(c_{\infty}, \phi_{\infty}, \nu_{\infty}, n_{\infty}, r_{\infty}, \pi_{\infty}, k_{\infty}\right)$ by the magnitude of $10^{-8}$ and moved backwards in time (simply by solving the system $\dot{x}=-f(x)$ rather than $\dot{x}=f(x)$ ). The differential equation system was solved with the standard Runge-Kutta method of order 4. As soon as one of the sluggish variables $n$ or $k$ moved through its initial condition $n_{0}$ or $k_{0}$, respectively, the algorithm stopped and calculated the percentage deviations of i) the starting points from the new steady state values and ii) the deviation of the endpoints from the initial conditions. The sum of the squared deviations was minimized using a Newton-Raphson algorithm. The percentage deviations amounted to less than $0.1 \%$ in each case.

\section{Balanced growth analysis}

In this section, we study the effects of monetary policy on the balanced growth path. Along the balanced growth path, the endogenous variables consumption $c$, capital $k$, output $y$, wages $w$, real money balances $m$, search effort $s$, employment $n$, vacancies $v$, the rate of inflation $\pi$, and the interest rate $r$ are all constant.

\subsection{Search externalities and monetary policy}

The effects of a change in the money growth rate on equilibrium values of the endogenous variables are presented in figure 1 for $\mu \in[-0.01,0.03]$. Following a rise in the money growth rate $\mu$, the rate of inflation $\pi$ goes up and households substitute leisure for consumption due to the presence of the cash-in-advance constraint (4). Agents increase leisure by reducing

\footnotetext{
${ }^{6} \mathrm{~A}$ description of this technique is provided by Judd (1998).
} 
their search effort $s$. For given job finding probability $q$, this effect reduces equilibrium employment $n=q s / \theta$. However, the job finding probability $q$ increases as firms increase their vacancies $v$. For the benchmark calibration, the latter effect dominates and equilibrium employment increases. There are two opposing effects of a higher inflation rate on the optimal number of posted vacancies. On the one hand, there are less agents searching for a job reducing the rate $\vartheta$ at which firms can fill a vacancy. On the other hand, high inflation reduces the optimal level of consumption. Households substitute capital $k$ for real money balances $m$. As a consequence, the marginal disutility from working (relative to the marginal utility of consumption) and, hence, the reservation wage decrease. According to (20), wages fall (compare also figure 1). Even though the rate at which agents fill their vacancies decreases, the fall in wages induces firms to increase their hiring activities.

$<$ - insert figure 1 here $->$

The quantitative effects are modest. A cut of the quarterly money growth rate $\mu$ (and, consequently, the inflation rate $\pi$ ) from $1.3 \%$ to $0 \%$ reduces employment from 0.6392 to 0.6379 . Households decrease their capital holdings by $0.19 \%$, while consumption increases by $0.25 \%$. As a consequence, wages rises by $0.64 \%$ and firms post less vacancies. The cut in vacancies, however, is considerable and amounts to $5.0 \%$. Instantaneous utility $U(c, s, n)$ initially increases with higher inflation $\pi$ as the utility from increased leisure compensates for the decrease in utility from consumption. Instantaneous utility is maximized for $\pi_{\max }=0.0 \%$. Notice, that in our benchmark calibration, a nominal interst rate of zero is not steady-state utility maximizing due to the presence of search in the labor market. Higher inflation helps to lessen wage pressure and results in the posting of more vacancies.

In order to compare the steady-state utility effects of different monetary 
policies, we take the benchmark equilibrium as presented in table 1 as our reference economy. As suggested by McGrattan (1994), the change in utility $\Delta_{c}$ is computed as the compensation in consumption required in order to make the household indifferent between the reference economy and an economy under an alternative monetary policy. ${ }^{7}$ A reduction from the benchmark money growth rate $\mu=1.3 \%$ to the steady-state utility-maximizing money growth rate $\mu_{\max }=0.0 \%$ results only in a small utility gain of $\Delta_{c}=0.03 \%$.

\subsection{Sensitivity analysis}

Our qualitative results as presented in the previous section and as summarized in figure 1 are robust with regard to the choice of the parameters except for the two parameters $\eta$ and $\gamma^{8}$ If the labor supply elasticity $\epsilon$ increases (ie $\eta$ decreases), the decline of the search effort $s$ following a rise in inflation is more pronounced. Similarly, a decline in the elasticity of vacancies in job matches $\gamma$ results in a smaller response of firms' vacancy posting to lower wages $w$. As a consequence, for lower values of $\eta$ and $\gamma$, the employment effect as resulting from the decline in search effort may overcompensate the employment effect stemming from the increase in vacancies. As can be seen in figure 2, employment $n$ decreases for a quarterly inflation rate in excess

\footnotetext{
${ }^{7}$ To be more specific, if $c, s$, and $n$ denote consumption, employment and search effort in the benchmark equilibrium and $c^{\prime}, s^{\prime}$, and $n^{\prime}$ are the corresponding steady state values in the new equilibrium, the consumption equivalent change is computed from $U((1+$ $\left.\left.\Delta_{c}\right) c, s, n\right)=U\left(c^{\prime}, s^{\prime}, n^{\prime}\right)$.

${ }^{8}$ More specifically, following a change of either $\lambda \in\{0.25,0.6\}, \kappa \in\{1,5\}, \sigma \in\{1,4\}$, or $\psi \in\{0.25,1\}$, employment is found to be a positive function of moderate money growth rates $\mu \in[-0.01,0.03]$. Furthermore, the utility-maximizing inflation rate $\pi_{\max }$ is sensitive with regard to the choice of $\psi$ and, to a much smaller extent, to the choice of $\sigma$. The steady-state utility-maximizing inflation rate is well above zero for a smaller share $\psi$ of the cash goods. For $\psi=0.5$, the quarterly inflation rate $\pi_{\max }$ amounts to $0.6 \%$. For the different parameter values $\sigma \in\{1,2,4\}, \pi_{\max }$ lies in the range between $-0.2 \%$ and $0.2 \%$.
} 
of $\pi=1.4 \%$ for a choice of the parameters $\eta=2.5$ and $\gamma=0.4$. The qualitative behavior of output is similar to the one of employment; in the case $(\eta, \gamma)=(2.5,0.4)$, the output-maximizing inflation rate is equal to $\pi=1.5 \%$ (not illustrated). Furthermore, utility is maximized if the money growth rate $\mu$ (and, equivalently, the inflation rate $\pi$ ) is chosen well below zero for a decline in $\eta$ or $\gamma$ to either 2.5 or 0.4 , respectively. For $\eta=2.5$ and $\gamma=0.4$, in particular, our steady-state analysis provides support for a zero nominal interest rate policy.

$<$ - insert figure 2 here $->$

As our main result from the balanced-growth analysis, we concede that both the employment and steady-state utility-maximizing monetary policies depend crucially on the elasticity of labor supply and the elasticity of vacancies in job matches and may well imply near-zero inflation rates. ${ }^{9}$ For both critical parameters, empirical estimates vary considerably. Our benchmark case for the labor supply elasticity $\epsilon=0.4$ is taken from Killingsworth (1983) and has been applied by Shi/Wen (1999) in computable general equilibrium (CGE) analysis. Other CGE studies even apply higher values of $\epsilon$. For example, Lucas (1990) uses a value of $\epsilon \in[0.5,5]$, while Jones et al. (1993) even take a value as high as 7.09 for the upper limit of $\epsilon$. Similarly, the elasticity of vacancies in job matches $\gamma$ has been estimated with British data and with

\footnotetext{
${ }^{9}$ The qualitative effect of the inflation rate on employment and utility further depends on the specification of the CIA constraint. If also investment purchases must be made with currency, $P\left(\psi_{0} c+\psi_{1}(\dot{k}+\delta k)\right) \leq M$, inflation has a more adverse effect on employment and output. See Abel (1985) for a study of the dynamics of capital accumulation in a economy with a CIA constraint on both consumption and investment, where leisure is the only credit good.
} 
US data by Pissarides (1986) and Blanchard/Diamond (1989) finding values of $\gamma=0.4$ and $\gamma=0.6$, respectively. The latter value has been applied by Shi/Wen (1999) which our benchmark calibration is based upon. Therefore, we carefully conclude that empirical observations do not allow for the firm conclusion that moderate rates of inflation and money growth in excess of zero are harmful to production and utility in the presence of labor market frictions.

\subsection{Investment tax credit}

The major explanation why positive nominal interest rates are optimal in our benchmark equilibrium is the portfolio substitution effect of inflation known as the Mundell-Tobin effect. Real money balances and capital are substitutes in the household portfolio and agents increase their portfolio demand for capital as the inflation rate goes up. Therefore, the natural question arises if subsidization of capital may be desirable and how the optimal monetary and tax policy would look like in such a case.

We, realistically, assume that additional government expenditures cannot be financed by lump sum taxes, but that the government has to finance additional subsidies to capital investment $\tau_{i}(\delta k+\dot{k})$ with the help of labor income taxes $\tau_{w} w n .{ }^{10}$ We consider the benchmark case with no government $\left(\tau_{w}=0, \tau_{i}=0\right)$ and analyze an increase of $\tau_{i}$ that is financed by an offsetting increase in $\tau_{w}$. Interestingly, the steady-state utility maximizing inflation rate $\pi_{\max }$ remains fairly constant. For $\tau_{i} \in\{1 \%, 2 \%, 5 \%, 10 \%\}, \pi_{\max }$ amounts to approximately $-0.2 \% . \pi_{\max }$ drops below $-0.5 \%$ only for values of $\tau_{i}$ in excess of $30 \%$. In addition, the steady-state utility-maximizing investment subsidy

\footnotetext{
${ }^{10}$ In this regard, we follow the recent literature on optimal monetary policy in the presence of distortionary taxation cited in the introduction.
} 
rate $\tau_{i}$ is found to amount to $50.0 \%$ with a corresponding value of $\pi_{\max }$ at the lower bound of the interval $[-0.01,0.03]$. The consumption equivalent steady-state utility change associated with a tax policy $\tau_{i}=50.0 \%$ and a monetary policy with $\mu=-1.0 \%$ amounts to $8.3 \%$.

\section{Dynamic welfare analysis of inflation}

In this section, the welfare costs of moderate rates of inflation are examined. As argued in the introduction, a sensible welfare analysis cannot ignore the transition dynamics following a change in monetary policy. For this reason, the dynamics are computed with the help of equations (2), (5), (7), (16), (21), (22), and (23). The effects of a permanent and unexpected decrease of the quarterly money growth rate from $1.3 \%$ to $0 \%$ at time 0 are displayed in figure 3 for consumption $c$, employment $n$, search effort $s$, vacancies $v$, output $y$, and capital $k$. The transition takes approximately 4 years. After this period, the deviation of the endogenous variables $c, n, s, v$, and $k$ from the new steady-state values is less than $0.1 \%$, respectively (compare figure 3 ). In the new steady state with $\pi=0 \%$, agents substitute real money balances for capital and the capital stock $k$ declines. Agents also increase consumption $c$ as the inflation tax is reduced. Higher consumption results in higher wages $\mathrm{w}$ (not illustrated) and it is less profitable for the firms to post vacancies $v$. As the response of vacancies to a decline in inflation is more pronounced than the increase of search effort, employment declines. Immediately following the increase of money growth at time 0 , consumption $c$ overshoots its new steady state value and increases by $8 \%$. Notice that employment is a fastmoving sluggish variable compared to the other sluggish variable, the capital stock, and employment even undershoots its new steady state value. ${ }^{11}$ After

\footnotetext{
${ }^{11}$ This kind of behavior is closely related to findings by Merz (1995). Merz studies the
} 
approximately one year, employment gradually increases towards its new steady state value, and agents start to decrease their search effort $s$ so that leisure remains approximately unchanged. As a consequence, firms can fill their vacancies at a lower rate $\vartheta$ and reduce their posting of vacancies. The behavior of output $y$, finally, closely mimics the behavior of employment.

$<$ - insert figure 3 here $->$

Welfare effects of a change in monetary policy are calculated by the change in utility (1) of the representative agent. In particular, we explicitly consider the change in utility during transition to the new steady state. The welfare gain of moving from allocation $\{c, s, n\}_{0}^{\infty}$ to allocation $\left\{c^{\prime}, s^{\prime}, n^{\prime}\right\}_{0}^{\infty}$ will again be measured by the consumption equivalent increase $\Delta_{c}$ :

$$
\int_{0}^{\infty} U\left(\left(1+\Delta_{c}\right) c, s, n\right) e^{-\rho t} d t=\int_{0}^{\infty} U\left(c^{\prime}, s^{\prime}, n^{\prime}\right) e^{-\rho t} d t .
$$

There are two effects of a decline in the money growth rate on welfare. First, the level of consumption increases. Second, agents increase leisure $1-s-$ $n$ immediately after the change in the monetary growth rate, but leisure declines below the old steady value after approximately one year. Following an unexpected once and for all change in monetary policy to $\mu=0$, welfare of the representative households increases by $0.065 \%$ of consumption. The inflation rate $\pi_{\max }=0 \%$ that maximizes steady-state utility, however, is not optimal once we also consider the transition to the new steady state. In fact, the optimal inflation rate is below zero and amounts to $\pi_{o p t}=-0.6 \%$ with a corresponding welfare gain equal to $\Delta_{c}=0.079 \%$. The optimal inflation business cycle behavior of a model with search unemployment and two sluggish variables, employment and capital. In particular, she shows that the impulse response of employment to a productivity shock is characterized by persistence and displays similar overshooting features as employment in our model. 
rate $\pi_{o p t}$ is even lower than the steady-state utility maximizing inflation rate $\pi_{\max }$ because consumption and, therefore, utility overshoots its new steady state value during transition (while the effect of the drop in leisure on utility is less pronounced). Notice further that the magnitude of the effect is in accordance with previous studies on the welfare costs of inflation in monetary general equilibrium models such as Cooley/Hansen (1989), Gomme (1993), or Wu/Zhang (1998).

$<-$ insert table 2 here $->$

Not surprisingly, the optimal money growth rate depends crucially on the elasticity of labor supply and the elasticity of vacancies in job matches. Table 2 summarizes the effects of moderate inflation for different values of $(\eta, \gamma)$. In the first row, the welfare gain of reducing the money growth rate to zero once and for all is presented for different values of $\eta$ and $\gamma$. For example, the reduction of the quarterly inflation rate from $1.3 \%$ to $0 \%$ for lower, but still empirically reasonable values of $\eta=2.5$ and $\gamma=0.4$ results in a welfare gain of $0.38 \%$ of total consumption. In the second row, the steady state inflation rate of the optimal monetary policy is displayed. The third row presents the welfare gain associated with the optimal monetary policy. Optimal money growth rates $\mu$ vary between $-0.6 \%$ and $-1.0 \%$ in the cases considered with corresponding nominal interest rates in the range of $0.4 \%$ to $0 \%$ (we only analyzed nonnegative nominal interest rates, $r+\pi \geq 0$ so that the cash-inadvance constraint binds). ${ }^{12}$ For lower values of $\eta$ and $\gamma$, therefore, it may

\footnotetext{
${ }^{12}$ In the working paper version of this paper, we also analyze the case of endogenous growth based on the model of Romer (1986). In the presence of a production externality of aggregate capital, the optimal inflation rate may be substantially higher and may well be in excess of zero (see Heer, 2000).
} 
well be optimal to reduce the nominal interest rate to zero even in the presence of labor market frictions. Again, the analysis in this section suggests that firm conclusions about the quantitative effects of a zero-nominal interest policy on welfare are difficult to obtain given the variety of empirical evidence on the values of the labor supply elasticity and the elasticity of vacancies in job matches.

\section{Conclusion}

This paper has examined the welfare costs of moderate inflation in a search equilibrium model. Our results challenge conventional wisdom that higher rates of inflation reduce employment, output, and welfare unanimously. As our first main result, low rates of inflation are demonstrated to reduce employment and output in the benchmark calibration of our model for the US economy, even though the quantitative effect is small. It is also straightforward to show that the reduction of employment also results in a lower growth rate in models of endogenous growth (see Heer, 2000). As our second main result, the optimal quarterly inflation rate is shown to be negative and amounts to $-0.6 \%$ in our benchmark case. Employment effects of monetary policy and, to a smaller extent, the optimal inflation rate, however, depend on two parameters from the labor market. The lower the elasticity of labor supply and the elasticity of vacancies in job matches, the more likely is inflation to have adverse effects on both employment and welfare and the more pronounced is the quantitative welfare effect of a monetary policy that entails a zero nominal interest rate. For reasonable values for these two parameters, welfare gains from an optimal monetary policy are computed in the range of $0.08-0.65 \%$ of total consumption. 


\section{References}

Abel, A.B., 1985. Dynamic Behavior of Capital Accumulation in a CashIn-Advance Model. Journal of Monetary Economics 16, 55-71.

Blanchard, O.J., Diamond, P., 1989. The Beveridge Curve. Brookings Papers and Proceedings 69, 1-78.

Chari, V.V., Christiano, L.J., Kehoe, P.J., 1996. Optimality of the Friedman Rule in Economies with Distorting Taxes. Journal of Monetary Economics 37, 203-23.

Cooley, T.F., Hansen, G.D., 1989. The Inflation Tax in a Real Business Cycle Model. American Economic Review 79, 18-32.

Cooley, T.F., Hansen, G.D., 1991. The Welfare Costs of Moderate Inflation. Journal of Money, Credit, and Banking 23, 483-503.

Cooley, T.F., Hansen, G.D., 1995. Money and the business cycle, in: Cooley, T.F., ed., Frontiers of Business Cycle Research (Princeton University Press, Princeton) 175-216.

Correia, I., Teles, P., 1996. Is the Friedman rule optimal when money is an intermediate good? Journal of Monetary Economics 38, 323-44.

Correia, I., Teles, P., 1997. The Optimal Inflation Tax. Federal Reserve Bank of Minneapolis Working Paper No. 123.

Diamond, P.A., Mirrless, J.A., 1971a. Optimal taxation and public production I: Production efficiency. American Economic Review 61, 8-27. 
Diamond, P.A., Mirrless, J.A., 1971b, Optimal taxation and public production II: Tax rules. American Economic Review 61, 261-68.

Edwards, S., Végh, C.A., 1997. Banks and macroeconomic disturbances under predetermined exchange rates. Journal of Monetary Economics 40, 239-78.

Friedman, M., 1969. The Optimum Quantity of Money, in: Friedman, M., ed., The Optimum Quantity of Money and Other Essays (University of Chicago Press, Chicago) 1-50.

Gillman, M., 1993. The welfare cost of inflation in a cash-in-advance economy with costly credit. Journal of Monetary Economics 31, 97-115.

Gomme, P., 1993. Money and growth revisited: measuring the costs of inflation in an endogenous growth model. Journal of Monetary Economics $32,51-77$.

Grüner, H.P., Heer, B., 2000. Optimal flat-rate taxes on capital - a reexamination of Lucas' supply-side model. Oxford Economic Papers 52, 289-305.

Guidotti, P.E., Végh, C.A., 1993. The Optimal Inflation Tax When Money Reduces Transactions Costs: A Reconsideration. Journal of Monetary Economics 31, 189-206.

Hansen, G., 1985. Indivisible labor and the business cycle. Journal of Monetary Economics 16, 309-27. 
Heer, B., 2000. Welfare Costs of Inflation in a Dynamic Economy with Search Unemployment and Endogenous Growth. CESifo Working Paper No. 296.

Jones, L.E., Manuelli, R.E., Rossi, P.E., 1993. Optimal Taxation in Models of Endogenous Growth. Journal of Political Economy 101, 485-517.

Judd, K.L., 1998. Numerical Methods in Economics (MIT Press, Cambridge, MA).

Killingsworth, M.R., 1983. Labor Supply (Cambridge University Press, Cambridge).

Kydland, F., Prescott, E.C., 1982. Time to Build Aggregate Fluctuations. Econometrica 50, 1345-70.

Lucas, R.E., 1988. On the mechanics of economic growth. Journal of Monetary Economics 22, 4-42.

Lucas, R.E., 1990. Supply-Side Economics: An Analytical Review. Oxford Economic Papers 42, 293-316.

Lucas, R.E., 2000. Inflation and Welfare. Econometrica 68, 247-74.

Lucas, R.E., Stokey, N.L., 1983. Optimal Fiscal and Monetary Policy in an Economy without Capital. Journal of Monetary Economicy 12, 55-93.

Lucas, R.E., Stokey, N.L., 1987. Money and Interest in a Cash-In-Advance Economy. Econometrica 55, 491-514. 
McGrattan, E., 1994. The macroeconomic effects of distortionary taxation. Journal of Monetary Economics 55, 491-514.

Merz, M., 1995. Search in the Labor Market and the Real Business Cycle. Journal of Monetary Economics 36, 269-300.

Pissarides, C.A., 1986. Unemployment and Vacancies in Britain. Economic Policy 3, 499-559.

Pissarides, C.A., 1990. Equilibrium Unemployment Theory (Basil Blackwell, Cambridge, MA).

Romer, P.M., 1986. Increasing returns and long run growth. Journal of Political Economy 94, 1002-38.

Shi, S., Wen, Q., 1997. Labor market search and capital accumulation: Some analytical results. Journal of Economic Dynamics and Control 21, 1747-76.

Shi, S., Wen, Q., 1999. Labor market search and the dynamic effects of taxes and subsidies. Journal of Monetary Economics 43, 457-95.

Tobin, J., 1965. Money and economic growth. Econometrica 33, 671-84.

Woodford, M., 1990. The Optimum Quantity of Money, in: Friedman, M., Hahn, F.H., eds., Handbook of Monetary Economics, Vol. 2 (NorthHolland, Amsterdam) 1065-1152.

Wu, Y., Zhang, J., 1998. Endogenous growth and the welfare costs of inflation: a reconsideration. Journal of Economic Dynamics and Control 22, $465-82$. 
Table 1

Calibration of parameter values for the US economy

\begin{tabular}{|c|c|c|}
\hline Description & Function & Parameter \\
\hline \multicolumn{3}{|l|}{ preferences } \\
\hline utility function & $U=\frac{c^{1-\sigma}}{1-\sigma}-\beta \frac{(s+n)^{\eta}}{\eta}$ & $\begin{array}{l}\beta=2.596, \eta=3.5 \\
\sigma=2.0\end{array}$ \\
\hline time preference & $\rho$ & $\rho=0.01$ \\
\hline \multicolumn{3}{|l|}{ production } \\
\hline production function & $y=A k^{\alpha} n^{1-\alpha}$ & $A=1, \alpha=0.25$ \\
\hline depreciation & $\delta$ & $\delta=0.01$ \\
\hline vacancy costs & $\kappa v$ & $\kappa=4.01$ \\
\hline \multicolumn{3}{|l|}{ labor market } \\
\hline matching function & $L=L_{0} v^{\gamma} s^{1-\gamma}$ & $\gamma=0.6, L_{0}=1.0$ \\
\hline job separation rate & $\theta$ & $\theta=0.05$ \\
\hline wage bargaining power & $\lambda$ & $\lambda=0.4$ \\
\hline \multicolumn{3}{|l|}{ monetary parameters } \\
\hline money growth rate & $\mu$ & $\mu=1.3 \%$ \\
\hline CIA constraint & $\psi c \leq m$ & $\psi=0.84$ \\
\hline \multicolumn{3}{|l|}{ government } \\
\hline labor income tax rate & $\tau_{w}$ & $\tau_{w}=0$ \\
\hline investment tax credit & $\tau_{i}$ & $\tau_{i}=0$ \\
\hline
\end{tabular}


Table 2

Sensitivity analysis of optimal monetary policy

$\eta=3.5 \quad \eta=3.5 \quad \eta=2.5 \quad \eta=2.5$

$\gamma=0.6 \quad \gamma=0.4 \quad \gamma=0.6 \quad \gamma=0.4$

$\pi=0$

\begin{tabular}{lllll}
$\Delta_{c}$ & $0.065 \%$ & $0.131 \%$ & $0.094 \%$ & $0.381 \%$ \\
\hline
\end{tabular}

optimal inflation

\begin{tabular}{lcccc} 
rate $\pi \geq-1 \%$ & $-0.6 \%$ & $-0.8 \%$ & $-0.7 \%$ & $-1.0 \%$ \\
$\Delta_{c}$ & $0.079 \%$ & $0.596 \%$ & $0.482 \%$ & $0.650 \%$ \\
\hline
\end{tabular}




\section{Legends of figures}

Fig. 1: Steady-state effects of the money growth rate $\mu$

Fig. 2: Sensitivity analysis for $\eta$ and $\gamma$

Fig. 3: Transition dynamics following a decrease of $\mu$ from $1.3 \%$ to $0 \%$ 

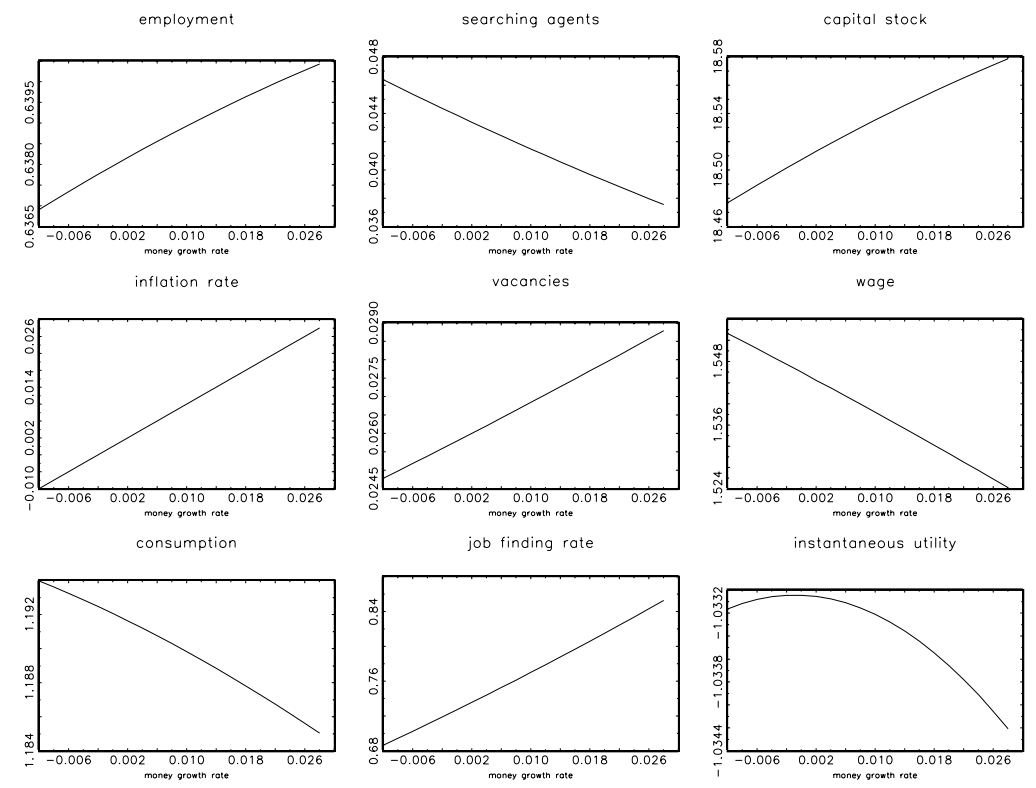
employment

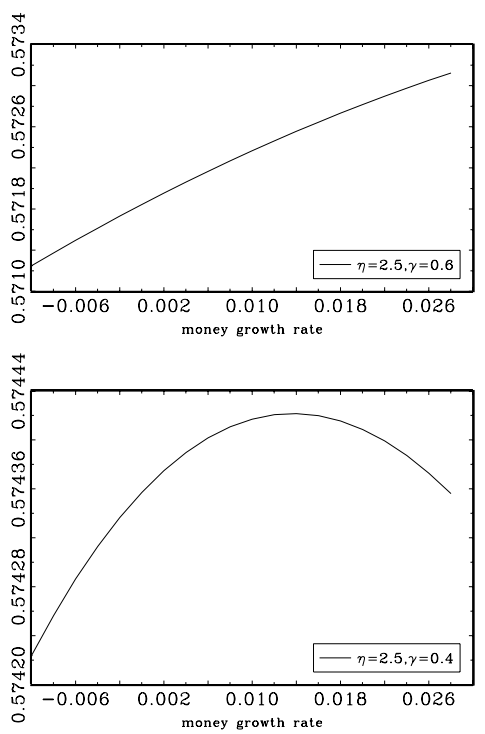

utility
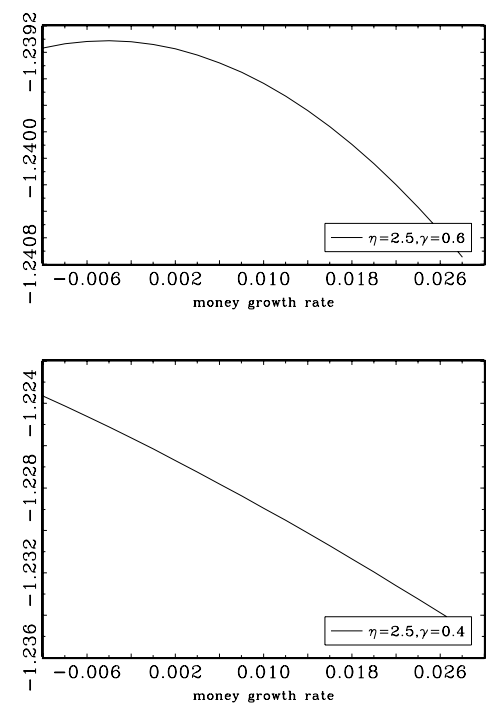

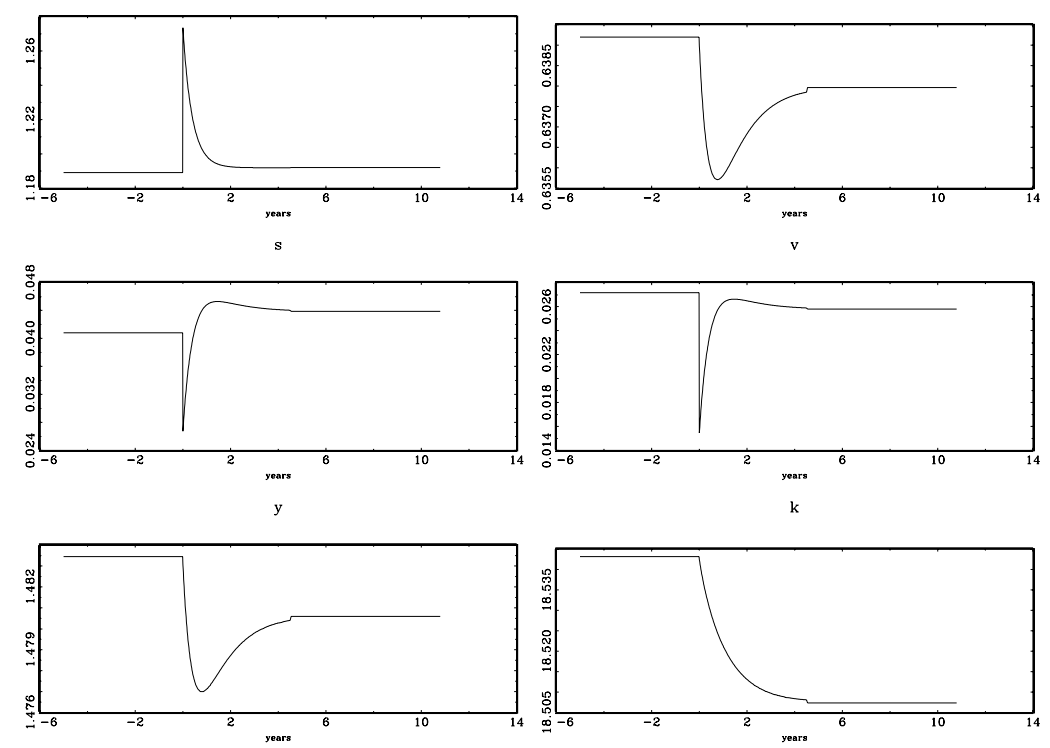